\title{
Corpectomy in Sub-Axial Cervical Fracture in Tertiary Center in Third World Country
}

\author{
MOHAMMED H. ALY, M.D.; AHMED H. ELASHRY, M.D. and AMR A.A.M. ELKATATNY, M.D. \\ The Department of Neurosurgery, Faculty of Medicine, Cairo University
}

\begin{abstract}
Background: Cervical spine injuries represent $5-10 \%$ of major injuries in post-traumatic patients. These injuries cause $6 \mathrm{~K}$ deaths and $5 \mathrm{~K}$ quadriplegic cases annually. The neurological defect happens due to disruption of the normal anatomy.

Aim of Study: Cervical corpectomy is a common spinal surgery procedure used to decompress the spinal cord in numerous degenerative, traumatic and neoplastic conditions. The aim of this study was to investigate the indications, complications and outcomes in past cervical corpectomy cases at one centre.
\end{abstract}

Patients and Methods: During the period of July 2019July 2020, corpectomy was performed on 14 patients with lower cervical spine fracture, fracture/dislocation by the author surgeons. Etiology for the cervical trauma of 14 patients was road traffic accidents. A standard anterior approach to the cervical column was applied to remove affected vertebrae and discs, including their upper and lower surfaces. Corpectomy was done with rounger and high-speed drills with image guidance. A PIRA mesh filled with bone was inserted into the space created by body and discs removed. A plate was inserted.

Results: In our series, $12(85.7 \%)$ were incomplete myelopathy (Grade III, IV, V). 7 of them improved after surgery ( $58.3 \%), 3$ unchanged (25\%), 2 passed away (16.7\%). We have 2 patients $(14.3 \%)$ with grade VI, of them 1 patient improved (50\%) and the other one did not improve (50\%). we have 12 patients $(85.7 \%)$ operated in 24 hours after trauma. 8 of them improved $(66.7 \%)$ and they were all the patients who were improved from the total $(8 / 14,57.14 \%)$. 2 cases only were postponed later than 24 hours. We have 2 patients had wound infection (14.3\%), 2 CSF collections (14. $3 \%), 2$ patients had difficulties in breathing (14.3\%), 4 patients suffered from bed sores $(28.6 \%)$. So total patients with complications were $8 / 14(57.14 \%)$. Four patients stayed 48 hours $(28.6 \%), 8$ patients $(57.1 \%)$ stayed for 72 hours. And 2 patientsstayed more than 72 hours $(14.3 \%)$.

Conclusion: We do not have actual number of incidences of road traffic accidents, but all our cases are due to accidents. We have C5 fracture was the most common segment. Most common age group affected was 21-30 with male predomi-

Correspondence to: Dr. Mohammed H. Aly, The Department of Neurosurgery, Faculty of Medicine, Cairo nance. Better neurological state pre-operative favors the outcome post-operative. Early surgery especially in 24 hours was related to clinical improvement. Decreasing infection may decrease mortality and improving the outcome. Shorter stay in ICU (less than 72 hours) post-operatively is a predictor for better outcome.

Key Words: Sub axial-Fractures-Cervical-Corpectomy.

\section{Introduction}

CERVICAL spine injuries represent $5-10 \%$ of major injuries in post-traumatic patients. These injuries cause $6 \mathrm{~K}$ deaths and $5 \mathrm{~K}$ quadriplegic cases annually. Most of the cervical injuries happen at C2 (1/3) and C6 or C7 (1/2) [1].

Injuries of cervical spine are classified according to several mechanism of injury. These include flexion, flexion-rotation, extension, extensionrotation, vertical compression, lateral flexion injuries [2].

The management differs according to type of fracture, instability and presence of cord compression from external fixation to surgical decompression and internal fixation [3].

The neurological defect happens due to disruption of the normal anatomy. The primary insult may be transection, compression or diameter of the cervical canal may play a role in the ongoing process. The inertia and torc of injury also play role in the severity [4].

The secondary cascade may propagate the spinal cord injury caudally or cranially. This explains why some patients may deteriorate in the acute postinjury period. The secondary cascade was suggested by Allen almost 100 years ago, who spotted the effects of ongoing hemorrhage, edema, and ischemia [5]. 
Vascular dysfunction may lead to ischemia and hemorrhage, inflammation with cellular and molecular mechanisms of continued neuronal and glial destruction, and other modes of injury including excitotoxicity and apoptosis [6].

To define factors associated with spinal stability we use the three-column theory of spinal anatomy, as in the thoracolumbar spine [6].

Table (1): Types and characteristics of lower Cx spine injuries [ ${ }^{7}$ ].

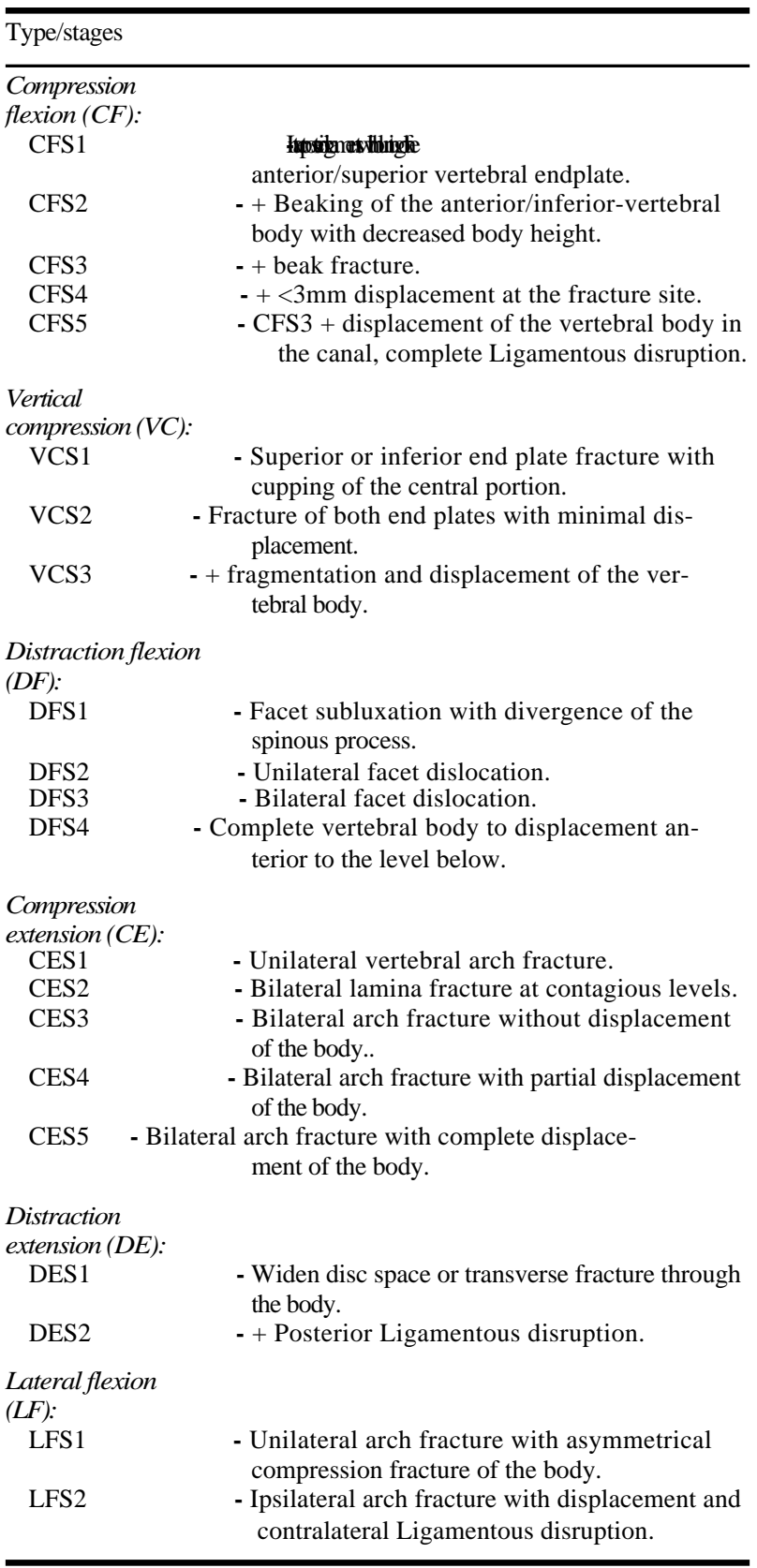

Principles used in the initial assessment of a patient with major trauma are outlined by the American College of Surgeons (ACS) in their
Advanced Trauma Life Support (ATLS) guidelines. The principals involved consist of:

1 - Preparation and transport.

2- Primary survey and resuscitation, including monitoring, urinary and nasogastric tube insertion, and imaging.

3- Secondary survey, including special investigations, such as CT scanning or angiography.

4- Ongoing reevaluation.

5- Definitive care.

The primary survey aims to identify and treat immediately life-threatening injuries relying on the ABCDE system. This system comprises airway control with stabilization of the cervical spine, breathing (work and efficacy), and circulation including the control of external hemorrhage, disability or neurologic status, and exposure or undressing of the patient while also protecting the patient from hypothermia [8].

\section{Material and Methods}

During the period of July 2019-July 2020, corpectomy was performed on 14 patients with lower cervical spine fracture, fracture/dislocation at Trauma Unit, Neurosurgery Department Cairo University Hospitals, by the author surgeons. 12 patients had a single level corpectomy and 2 patients with two levels Fig. (1). 12 patients were male and 2 females. Etiology for the cervical trauma of 14 patients was road traffic accidents. In the evaluation of cervical pathologies, a cervical plane images were taken, as well as computed tomography and magnetic resonance imaging. The plain images are for screening, CAT scans for confirmation and assessment of facets, MRIs for integrity of ligaments and discs. There were burst fracture in 12 cases and 2 with burst with retro pulsed vertebrae.

Our protocol was urgent application of Philadelphia hard neck collar on admission. We did not use traction as we have not any case with locked facet. Usage of methyl prednisolone after admission and diagnosis and intra-operative. Age distribution of cases illustrated in Fig. (2).

A standard anterior approach to the cervical column was applied to remove affected vertebrae and discs, including their upper and lower surfaces [9].

Corpectomy was done with rounger and highspeed drills with image guidance. A PIRA mesh filled with bone was inserted into the space created 
by body and discs removed. A plate was inserted into the anterior aspect of the body of the adjacent vertebrae including the graft in all patients. screws were used for plating Fig. (3). The patients were

Levels of corpectomy

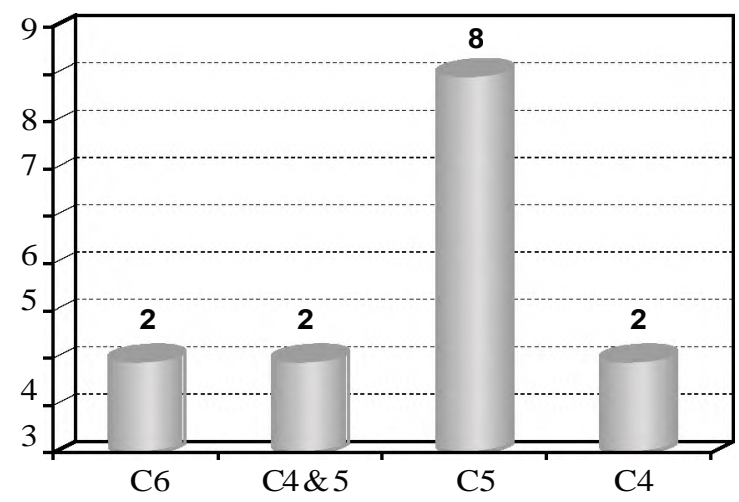

Fig. (1): Levels of corpectomy.
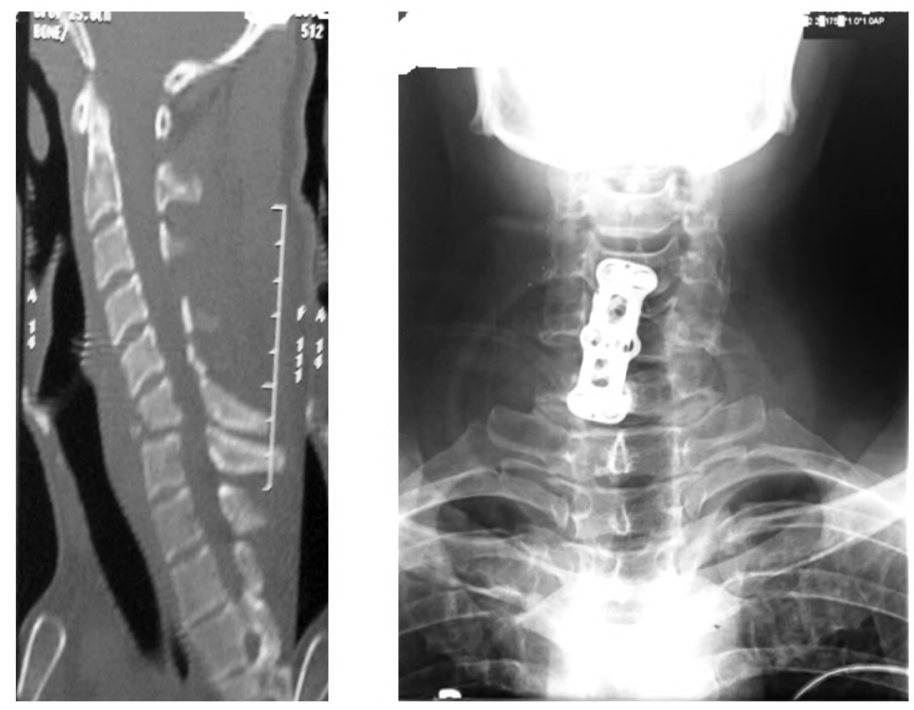

Fig. (3): Pre and post images of C6 corpectomy, PIRA mesh and plate.

We will assess the cases with the functional grading scale of Benzel and Larson [10].

- Grade I: Complete functional neuronal transection. No motor or sensory function below the level of injury.

- Grade II: Motor complete. No voluntary motor function below the level of injury, with preservation of some sensation.

- Grade III: Motor incomplete-non-functional. Minimal nonfunctional voluntary motor function below the level of injury.

- Grade IV: Motor incomplete functional. Unable to walk; some functional motor control below the level of injury.

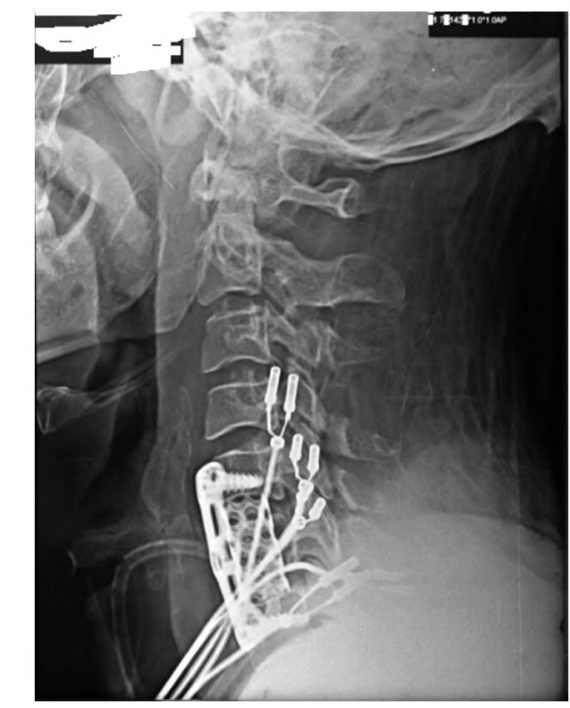

routinely mobilized with cervical collar as early as possible if ambulant. Cervical plain images and CAT scans were reviewed post for evaluation instrumentation and proper decompression.

Age distribution for cases

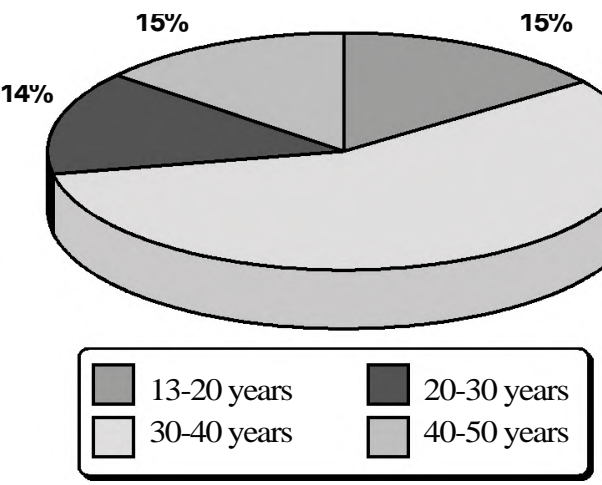

Fig. (2): Age distribution for cases.

- Grade V: Motor incomplete functional. Limited walking, lack of endurance or fear of falling.

- Grade VI: Motor incomplete functional. Unlimited walking, difficulties with micturition and slightly dis-co-ordinated gait.

- Grade VII: Normal.

\section{Results}

In our series, we summarize the neurological condition of our patients on admission and shortterm post-operative during hospital stay in (Table 2). Among our patients, 12 (85.7\%) were incomplete myelopathy (Grade III, IV, V). 7 of them improved after surgery $(58.3 \%), 3$ unchanged ( $25 \%), 2$ passed away (16.7\%) one due to respira- 
tory disability and the other due to bad general condition and accompanied injuries.

We have 2 patients $(14.3 \%)$ with grade VI, of them 1 patient improved $(50 \%)$ and the other one did not improve $(50 \%)$. So, we have 8 patients ( $57.14 \%$ ) improved after surgery, 4 not improved ( 28.57\%), 2 died (14.28\%). Fig. (4) showed all these results.

As the policy of our institute is to operate upon these cases as soon as possible, we trace the time it takes to be operated as in (Table 3). We have 12 patients $(85.7 \%)$ operated in 24 hours after trauma. 8 of them improved $(66.7 \%)$ and they were all the patients who were improved from the total ( $8 / 14,57.14 \%) .3$ unchanged (25\%). 1 died (8.3\%) from poor general condition and associated injuries.

2 cases only were postponed later than 24 hours. One was in spinal shock and we wait till the patient was vitally stable. 1 case did not improve $(50 \%)$, and 1 died (50\%). The one who died, was the one with spinal shock and died of respiratory arrest.

We noticed that the earlier the surgery the more improvement expected as in Fig. (5). Also, the better the neurological grade pre-operative the more improvement we expect as in Fig. (4). pvalue cannot be calculated due to small number of cases, further cases need to be traced to reach statistical significance.

Complications were summarized in (Table 4). We have 2 patients had wound infection (14.3\%), one of them resolved with antibiotics and the other one needed debridement without removal of the instrumentation. We had 2 CSF collections (14.3\%) both resolved with conservative management, one of them was with wound infection which resolved with antibiotics.

2 patients had difficulties in breathing (14.3\%), one had this pre-operative and it lasted post and the patient died. The other one had difficulties post and improved with steroids and physiotherapy. 4 patients suffered from bed sores (28.6\%), 2 of them improved with care and frequent mobilization, one needed debridement (the one with difficulty breathing which improved) and one died. So total patients with complications were $8 / 14(57.14 \%)$ showed in Fig. (6).

Length of stay in the ICU after surgery was recorded in (Table 5). Four patients stayed 48 hours ( $28.6 \%), 2(2 / 14,14.3 \%)$ improved and 2 unchanged from pre-operative neurological state. 8 natients $(57.1 \%)$ staved for 72 hours. 6 of them improved $(6 / 14,42.86 \%)$, one unchanged and one died of respiratory arrest $(1 / 14,7.14 \%) .2$ patients stayed more than 72 hours $(14.3 \%)$, one unchanged condition and the other one died from poor general condition and associated injuries $(1 / 14,7.14 \%)$.

So, the 8 improved patients stayed in the ICU for less than 72 hours as showed in Fig. (7), and this may be a cut off for prediction of improvement in the neurological state in the short term followup.

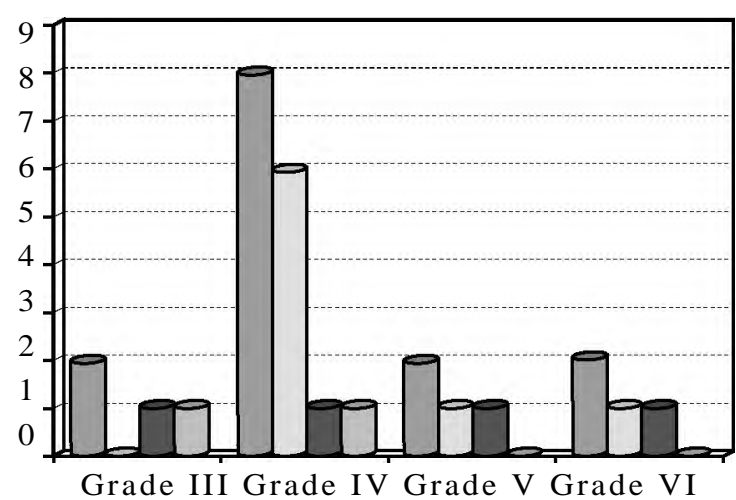

$\begin{array}{ll}\text { Total number pre-operative } & \text { Unchanged } \\ \text { Improved even one grade } & \text { Died }\end{array}$

Fig. (4): Relation of the total number pre and post-operative and the neurological grade,

Table (2): The cases with the functional grading scale of Benzel and Larson [10].

\begin{tabular}{lcccc}
\hline \multicolumn{2}{c}{ Pre-operative } & \multicolumn{3}{c}{ Post-operative } \\
\hline $\begin{array}{l}\text { Neurological } \\
\text { grade }\end{array}$ & Number & $\begin{array}{c}\text { Patients showed even } \\
\text { one grade improvement }\end{array}$ & \multicolumn{2}{c}{ Un P a s s e d } \\
changed & away \\
\hline Grade III & 2 & 0 & 1 & 1 \\
Grade IV & 8 & 6 & 1 & 1 \\
Grade V & 2 & 1 & 1 & 0 \\
Grade VI & 2 & 1 & 1 & 0 \\
\hline Total & 14 & 8 & 4 & 2 \\
\hline
\end{tabular}

Table (3): Time of surgery after trauma.

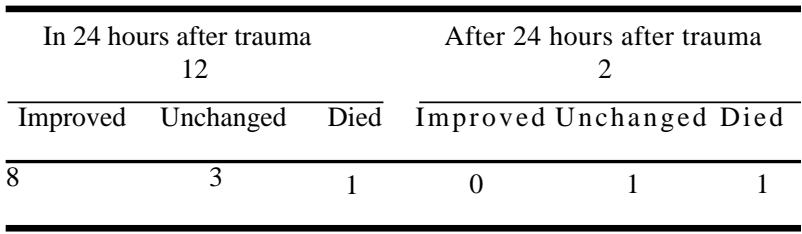

Table (4): Number of complications in our series.

\begin{tabular}{|c|c|c|c|c|c|c|c|c|}
\hline & $\begin{array}{l}\text { Wound } \\
\text { infection } \\
2 \\
2\end{array}$ & colI & $\begin{array}{l}\text { ection } \\
\text { Csf } \\
2\end{array}$ & Diffic & ulty & & & \\
\hline $\begin{array}{l}\text { Impro- } \\
\text { ved }\end{array}$ & $\begin{array}{c}\text { dement } \\
\text { debri- } \\
\text { Need }\end{array}$ & esol- & $\begin{array}{c}\text { Need } \\
\text { inter- } \\
\text { vention }\end{array}$ & $\begin{array}{c}\text { Impro- } \\
\text { ved }\end{array}$ & Died & $\begin{array}{c}\text { Impro- } \\
\text { ved }\end{array}$ & $\begin{array}{c}\text { Need } \\
\text { debri- } \\
\text { dement }\end{array}$ & Died \\
\hline 1 & 1 & 2 & 0 & 1 & 1 & 2 & 1 & 1 \\
\hline
\end{tabular}


Table (5): Period of ICU stay after surgery.

\begin{tabular}{|c|c|c|c|c|c|c|c|c|}
\hline \multicolumn{3}{|c|}{$\begin{array}{c}48 \text { hours } \\
4\end{array}$} & \multicolumn{3}{|c|}{$\begin{array}{c}72 \text { hours } \\
8\end{array}$} & \multicolumn{3}{|c|}{$\begin{array}{c}\text { More than } 72 \text { hours } \\
2\end{array}$} \\
\hline $\begin{array}{l}\text { Impro- } \\
\text { ved }\end{array}$ & $\begin{array}{l}\text { Uncha- } \\
\text { nged }\end{array}$ & Died & $\begin{array}{l}\text { Impro- } \\
\text { ved }\end{array}$ & $\begin{array}{l}\text { Uncha- } \\
\text { nged }\end{array}$ & Died & $\begin{array}{l}\text { Impro- } \\
\text { ved }\end{array}$ & $\begin{array}{l}\text { Uncha- } \\
\text { nged }\end{array}$ & Died \\
\hline 2 & 2 & 0 & 6 & 1 & 1 & 0 & 1 & 1 \\
\hline
\end{tabular}

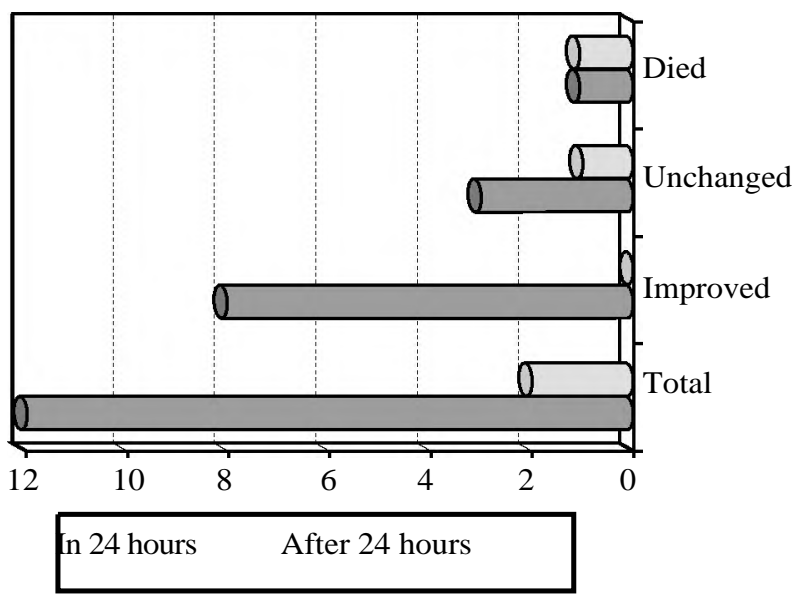

Fig. (5): The timing of surgery after trauma.

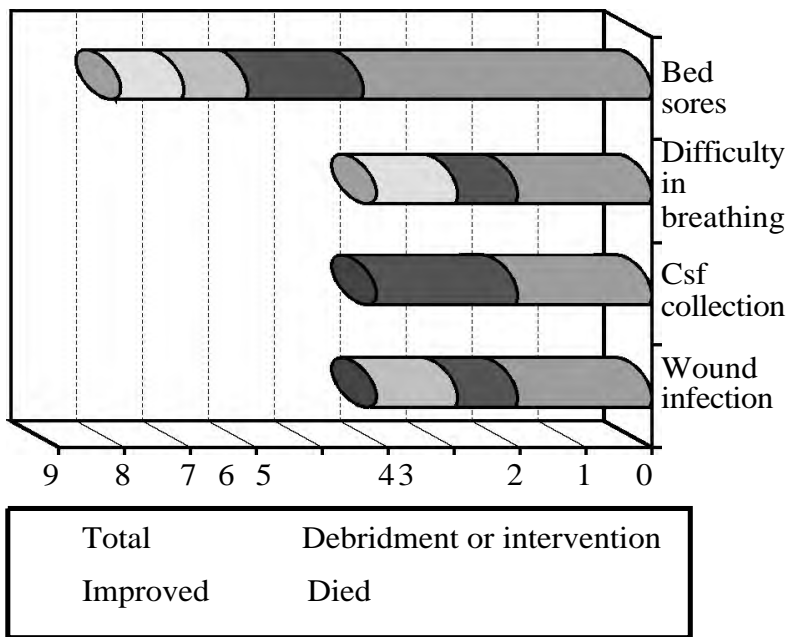

Fig. (6): Complication types and fate.

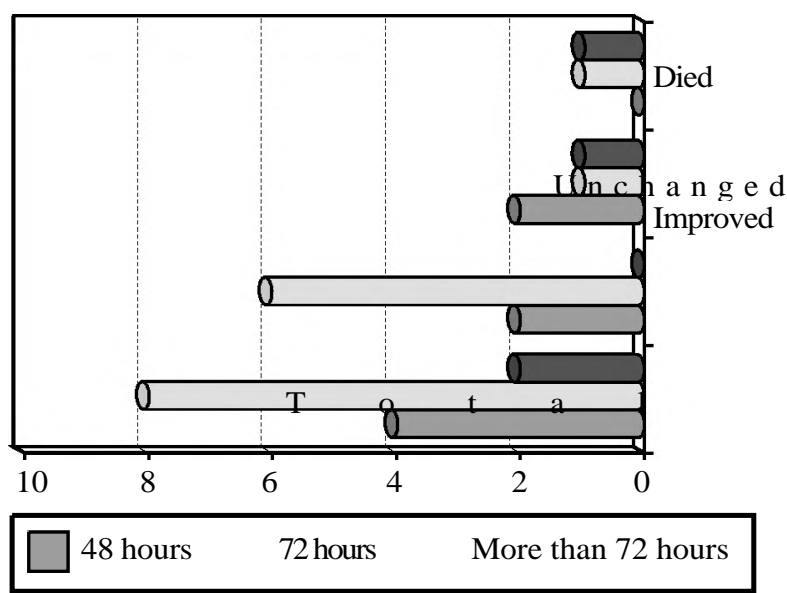

Fig. (7): Length of stay in ICU and outcome accourding to neurological condition.

\section{Discussion}

Regarding the levels of vertebrae affected, we found $\mathrm{C} 5$ is the most common segment to be affected, then C4 \& 5, C6 and C4. This is different from what was published. C7 then C6 and C5 in order. This study was done retrospective on large scale and the most common affected segment was different from ours [11].

Also, we had more males $(85.7 \%)$. This is the same as what reported in the same study [11]. We found that the most common age group was (2030). The sekhar paper found that the incidence of cervical spine trauma was highest in the age group of 21-30 years followed by 31-40 [11]. We did not have any pediatric patients Amy Peykoff Hardin [ 12] and no ethnic distribution as no different races present frankly in our country. Cervical spine is a fulcrum between rigid thoracic spine and relatively mobile head. Excessive motion at this level from acceleration deceleration leads to bony and ligamentous injuries. That's why in our series and among colleagues, road traffic accidents are the leading cause of cervical fractures [13]. Trauma studies done in Canada, India, China, Iran, and Africa have found that road traffic accidents are the most common cause of spine trauma [14-16]. European countries have achieved a shift from road traffic accident to falls as the most frequent etiology of spin injury due to rigid safety measures [ 17,18]. We in Egypt do not have registry or national study to know the actual numbers, but in our study all patients were from motor traffic accidents.

We trace our cases through the pre-operative state and post-operative state and timing to surgery. Cervical cord trauma with sub-axial cervical fracture is a serious condition. Two related problem are in these patients: A neurologic injury by present compression, and the instability that prevents care, mobilization, rehabilitation and delay management of co-morbidities [19,20]. Spinal stabilization by the neck collar, if needed early surgical decompression, and steroids injection and patient stabilization vitally in the form of perfusion pressure augmentation through good hydration and blood pressure management are advisable. Neuroprotection should be target whether on short term or long term, including pharmacological methods and nonpharmacologic interventions [21]. An unstable cervical spine needs surgical intervention, as it can affect stability and alignment which may cause neurological compression $[\mathbf{2 2 , 2 3 ]}$. The anterior approach has received interest among surgeons due to ability of decompression of the spinal canal and removing 
any discs or bony fragments as in Fig. (8) and restoration of the height and curve [24-26]. The time from injury and admission to surgery was noticed crucially with the basic neurological state. we found that the basic neurology of the patient is predictor of the hopeful improvement. $12(85.7 \%)$ were incomplete myelopathy. 7 of them improved after surgery (58.3\%). 2 patients (14.3\%) with grade VI, of them 1 patient improved (50\%). So, we have 8 patients $(57.14 \%)$ improved after surgery, 4 not improved (28.57\%), 2 died (14. $28 \%$ ). Fig. (4) showed all these results. So, decompression is of benefit in the area of improving the neurologicalstate.

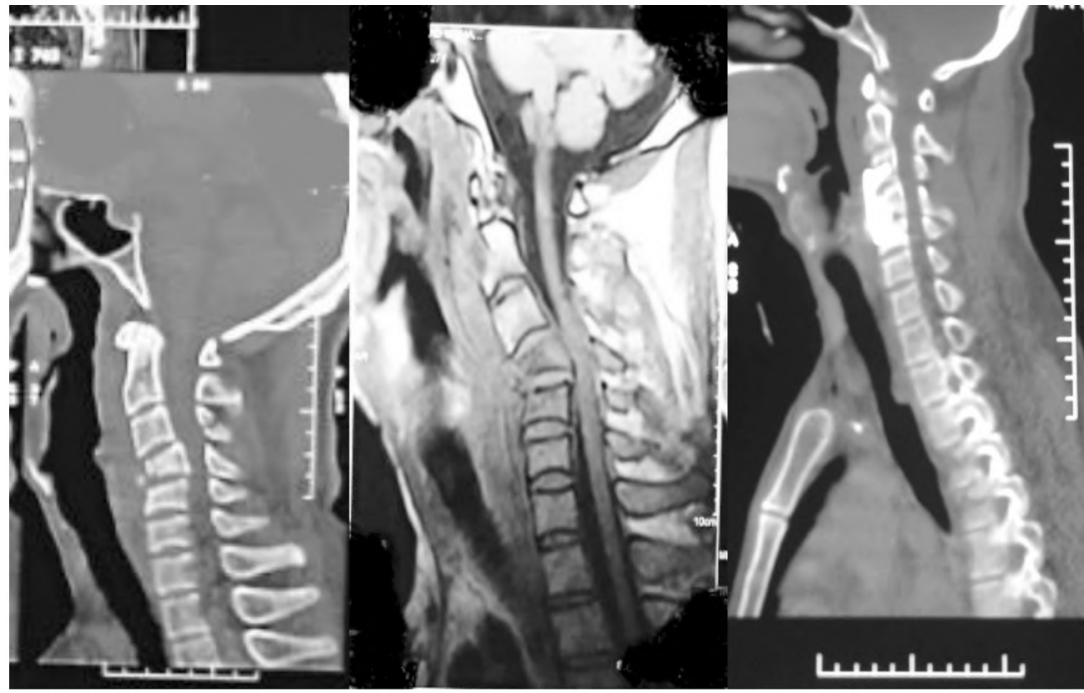

Fig. (8): C4 cervical

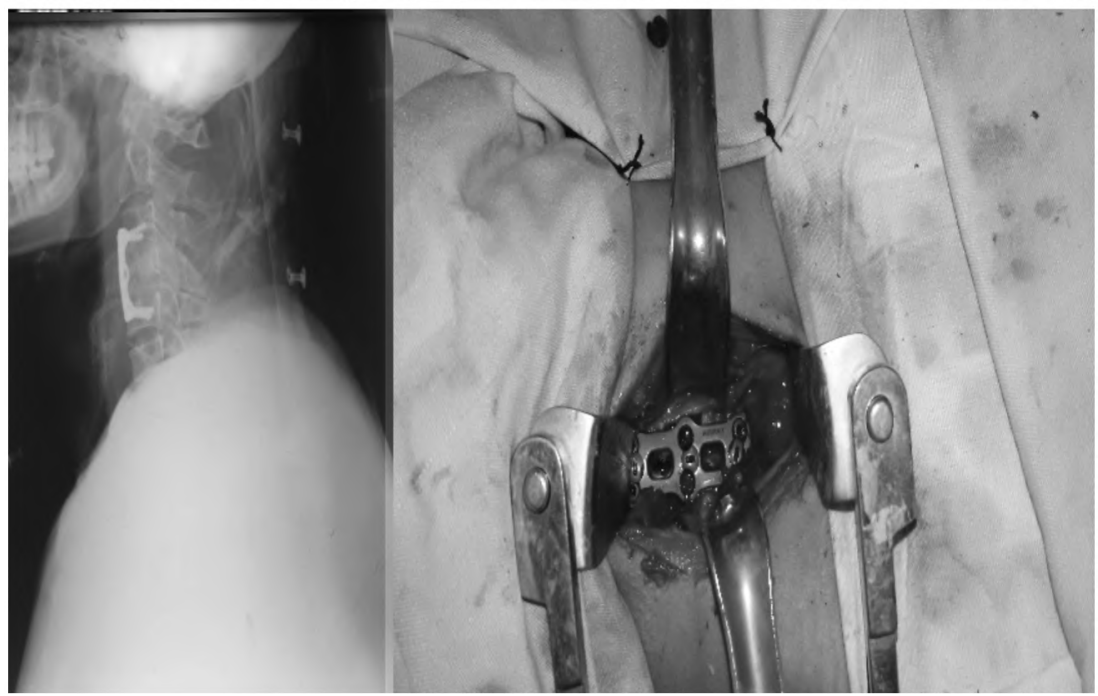
fracture pre-operative $\mathrm{CT}$ and MRI, post CT and Xray, intra operative plate.

A longer time of compression was associated with reduced electrophysiological recovery, pathological changes and functional outcome in the literature [21]. We have 12 patients $(85.7 \%)$ operated in 24 hours after trauma. 8 of them improved $(66.7 \%)$ and they were all the patients who were improved from the total $(8 / 14,57$. 14\%). 3 unchanged (25\%). 1 died (8.3\%) from poor general condition and associated injuries. 2 cases only were postponed later than 24 hours. One was in spinal shock and we wait till the patient was vitally stable. 1 case did not improve $(50 \%)$, and 1 died $(50 \%)$. The one who died, was the one with spinal shock and died of respiratory arrest. So time is very important and should be done as early as the patient is fit for to improve the chances for neurological recovery and decrease hospital stay and mortality. This is the same as what many papers suggest [21,27]. We found that the average time from injury to operation was one day in the functional restoration group. Delaying time from injury to operation (more than one day) can lead to poor prognosis after surgical treatment. Timing of surgery has been a debate. While theoretical and experimental animal studies showed that early intervention may give advantage for spinal cord injuries with cervical fractures, no clinical studies have showed this yet. Experts advised to interfere 
with in $8-24$ hours $[28,29]$. And this goes with what we found.

Complications were showed previously in Fig. ( 6). In literature, rates of any complication increased since 2005 (2005, 31.6\% vs. 2013, 36.2\%). Mortality was $6.6 \%$. Mortality decreased significantly from $6.8 \%$ in 2005 to $6.6 \%$ in 2013 [30]. In our series, total patients with complications were 8/14 ( $57.14 \%$ ) which was not that far from many reviews.

The most common complications in Passias et al., [30] were anemia (7.7\%), Acute Respiratory Distress Syndrome (ARDS) (6.6\%), bowel complications $(3.8 \%)$, and shock $(2.6 \%)$. Rates of paraplegia, bowel complications, bladder complications, neurologic symptoms, muscle weakness, shock, anemia, and Deep Vein Thrombosis (DVT) have all significantly increased since 2005. Rates of dysphagia, pulmonary complications, gastrointestinal complications, renal complications, and infection have all significantly decreased since 2005 . In our series, we have 2 patients had wound infection $(14.3 \%)$, one of them resolved with antibiotics and the other one needed debridement without removal of the instrumentation. We had $2 \mathrm{CSF}$ collections (14.3\%) both resolved with conservative management, one of them was with wound infection which resolved with antibiotics. 2 patients had difficulties in breathing (14.3\%), one had this preoperative and it lasted post and the patient died. The other one had difficulties post and improved with steroids and physiotherapy. 4 patients suffered from bed sores (28.6\%), 2 of them improved with care and frequent mobilization, one needed debridement (the one with difficulty breathing which improved) and one died. great care should be given to care of bed ridden patient and to the comorbidities to avoid losing patients. Regarding our mortalities, they were linked to infection whether through the wound or the bed sores. So we have to guard against by usage of proper antibiotics and sterilization and disinfection techniques with proper handling of bed ridden patients.

Four patients stayed in ICU for 48 hours ( $28.6 \%), 2(2 / 14,14.3 \%)$ improved. 8 patients ( $57.1 \%$ ) stayed for 72 hours. 6 of them improved ( $6 / 14,42.86 \%$ ), one unchanged and one died of respiratory arrest $(1 / 14,7.14 \%) .2$ patients stayed more than 72 hours $(14.3 \%)$, one unchanged condition and the other one died from poor general condition and associated injuries $(1 / 14,7.14 \%)$. All the improved patients $(8 / 14,57.14 \%)$ stayed in the ICU for less than 72 hours as showed in Fig. ( 7 ), and this may be a cut off for prediction of improvement in the neurological state in the short term follow-up and predictor of better outcome.

\section{Conclusion:}

We do not have actual number of incidences of road traffic accidents, but all our cases are due to accidents. We have C5 fracture was the most common segment. Most common age group affected was 21-30 with male predominance. Better neurological state pre-operative favors the outcome postoperative. Early surgery especially in 24 hours was related to clinical improvement. Decreasing infection may decrease mortality and improving the outcome. Shorter stay in ICU (less than 72 hours) post-operatively is a predictor for better outcome.

\section{References}

1- WINSLOW J.E. 3rd, HENSBERRY R., BOZEMAN W.P., et al.: Risk of thoracolumbar fractures doubled in victims of motor vehicle collisions with cervical spine fractures. J. Trauma, Sep., 61 (3): 686-7. doi: 10 1097/01.ta.0000196925. 99822.37, 2006.

2- JACOBS L.M. and SCHWARTZ R.: Prospective analysis of acute cervical spine injury: A methodology to predict injury. Ann. Emerg. Med., Jan., 15 (1): 44-9. Doi: 10.1016/ s0196-0644(86)80485-1, 1986.

3- NORDIN M., CARRAGEE E.J., HOGG-JOHNSON S., et al.: Assessment of neck pain and its associated disorders: Results of the Bone and Joint Decade 2000-2010 Task Force on Neck Pain and Its Associated Disorders. J. Manipulative Physiol. Ther., Feb., 32 (2 Suppl): S11740. doi: 10.1016/j.jmpt.2008.11.016, 2009.

4- AMAR A.P. and LEVY M.C.: Pathogenesis and pharmacological strategies for mitigating secondary damage in acute spinal cord injury. Neurosurgery, 44: 1027-40, 1999.

5- SAVAS P.: Biomechanics of the injured cervical spine in vaccaro AR ed: Fractures of the cervical, thoracic, and lumbar spine. New York, Marcel Dekker, inc., 3: 23-44, 2003.

6- OREN G. BLAM, DOUGLAS M. EHLER, WOLFAGEN RAUSHEGEN, et al.: Anatomy and pathophysiology in vaccaro AR ed: Fractures of the cervical, thoracic, and lumbar spine. New York, Marcel Dekker, Inc., 2: 9-23, 2003.

7- KAMRAN AFLATOON and JOHN J. CARBONE: Injuries of lower cervical spines, in Adult and pediatric spine, third edition, Lippincott, Williams and Wilkins, 34: 65968,2004

8- BRITT L.D., TRUNKEY D.D. and FELICIANO D.V.: eds. Acute Care Surgery Principles and Practice. Springer Verlag, 6: 120-32, 2007.

9- CLOWARD R.B.: Treatment of acute fractures and fracture dislocations of the cervical spine by vertebral-body fusion Report of eleven cases. J. Neurosurg., 18; 201209, 1961.

10- BENZEL E.C. and LARSON S.J.: Functional recovery after decompressive spine operation for spine fractures. 
11- SHEKHAR KHANPARA, DANIEL RUIZ-PARDO, SUSANNA C. SPENCE, O. CLARK WEST and ROY RIASCOS: Incidence of cervical spine fractures on CT: A study in a large level I trauma center. Emerg. Radiol., Feb., 27 ( 1): 1-8. doi: 10.1007/s10140-019-01717-9. Epub. 2019 Aug. 28, 2020.

12- AMY PEYKOFF HARDIN and JESSE M. HACKELL: Committee on Practice and ambulatory medicine, Age limit of pediatrics, Pediatrics, doi: 10.1542/peds.20172151. Epub 2017 Aug. 21, 2017.

13- TANAKA N., ATESOK K., NAKANISHI K., KAMEI N., NAKAMAE T., KOTAKA S. and ADACHI N.: Pathology and Treatment of Traumatic Cervical Spine Syndrome: Whiplash Injury. Adv. Orthop., Feb. 28; 4765050. doi: 10.1155/2018/4765050. PMID: 29682354; PMCID: PMC5851023, 2018.

14- WANG, HONGWEI, LIU, XINWEI, ZHAO, YIWEN, OU, LAN, et al.: Incidence and pattern of traumatic spinal fractures and associated spinal cord injury resulting from motor vehicle collisions in China over 11 years, Medicine: 95 (43): e5220 doi: 10.1097/MD.0000000000005220, 2016.

15- EL FATEMI NIZARE, et al.: Upper cervical spine injuries: A management of a series of 70 cases. Pan. African Medical Journal, 15: 57. doi: 10.11604/pamj.2013.15.57. 2316, 2013.

16- DRAULANS N., KIEKENS C., ROELS E., et al.: Etiology of spinal cord injuries in Sub-Saharan Africa. Spinal Cord., 49: 1148-54. https://doi.org/10.1038/sc.2011.93, 2011.

17- PHILIPP LEUCHT, KLAUS FISCHER, GERT MUHR and ERNST J. MUELLER: Epidemiology of traumatic spine fractures international journal of injured, 40 (2): 166-72, February 01, 2009, doi.org/10.1016/j.injury.2008. 06. 040, 2008.

18- FREDØ H.L., BAKKEN I.J., LIED B., et al.: Incidence of traumatic cervical spine fractures in the Norwegian population: A national registry study. Scand J. Trauma Resusc. Emerg. Med., 22: 78. https://doi.org/10. 1186/s13049-014-0078-7, 2014.

19- BRODKE D.S., ANDERSON P.A., NEWELL D.W., GRADY M.S. and CHAPMAN J.R.: Comparison of anterior and posterior approaches in cervical spinal cord injuries. J. Spinal Disord Tech., Jun., 16 (3): 229-35. doi: 10. 1097/00024720-200306000-00001. PMID: 12792335 , 2003.

20- KOIVIKKO M.P., MYLLYNEN P. and SANTAVIRTA S.: Fracture dislocations of the cervical spine: A review of 106 conservatively and operatively treated patients. Eur. Spine J., Nov., 13 (7): 610-6. doi: 10.1007/s00586004-0688-2. Epub 2004 Aug. 6. PMID: 15300472; PMCID: PMC3476653, 2004.

21- CAO B.H., WU Z.M. and LIANG J.W.: Risk Factors for Poor Prognosis of Cervical Spinal Cord Injury with Subaxial Cervical Spine Fracture-Dislocation After Surgical Treatment: A CONSORT Study. Med. Sci. Monit. 2019 Mar. 16; 25: 1970-5. doi: 10.12659/MSM.915700. PMID: 30877267; PMCID: PMC6433098, 2019.
22- WANG J., ELTORAI A.E.M., DePASSE J.M., DURAND W., REID D. and DANIELS A.H.: Variability in Treatment for Patients with Cervical Spine Fracture and Dislocation: An Analysis of 107,152 Patients. World Neurosurg. 2018 Jun., 114: e151-e157. doi: 10.1016/j.wneu.2018.02.119. Epub 2018 Mar. 6. PMID: 29501518, 2018.

23- GAO W., WANG B., HAO D., ZHU Z., GUO H., LI H. and KONG L.: Surgical Treatment of Lower Cervical Fracture-Dislocation with Spinal Cord Injuries by Anterior Approach: 5-to 15-Year Follow-Up. World Neurosurg., Jul., 115: e137-e145. doi: 10.1016/j.wneu.2018.03.213. Epub 2018 Apr. 6. PMID: 29631085, 2018.

24- GARVEY T.A., EISMONT F.J. and ROBERTI L.J.: Anterior decompression, structural bone grafting, and Caspar plate stabilization for unstable cervical spine fractures and/or dislocations. Spine (Phila Pa 1976). Oct., 17 (10 Suppl): S431-5. doi: 10.1097/00007632199210001 -00015. PMID: 1440039, 1992.

25- DONNARUMMA P., BOZZINI V., RIZZI G., BERARDI A. and MERLICCO G.: Surgical management of C-type subaxial cervical fractures using cervical traction followed by anterior cervical discectomy and fusion within $12 \mathrm{~h}$ after the trauma. J. Craniovertebr Junction Spine, Oct.Dec., 8 (4): 338-41. doi: 10.4103/jevjs.JCVJS_99_17. PMID: 29403246; PMCID: PMC5763591, 2017.

26- DVORAK M.F., FISHER C.G., FEHLINGS M.G., RAMPERSAUD Y.R., ONER F.C., AARABIB. and VACCARO A. R.: The surgical approach to subaxial cervical spine injuries: An evidence-based algorithm based on the SLIC classification system. Spine (Phila Pa 1976). Nov. 1; 32 ( 23): 2620-9. doi: 10.1097/BRS.0b013e318158ce16. PMID: 17978665, 2007.

27- SCHLEGEL J., BAYLEY J., YUAN H. and FREDRICKSEN B.: Timing of surgical decompression and fixation of acute spinal fractures. J. Orthop. Trauma, 10 ( 5): 323- 30. doi: 10.1097/00005131-199607000-00006. PMID: 8814573, 1996

28- COPLEY P., TILLIRIDOU V. and JAMJOOM A.: Traumatic cervical spine fractures in the adult. Br. J. Hosp. Med. (Lond), Sep. 2; 77 (9): 530-5. doi: 10.12968/hmed. 2016.77.9.530. PMID: 27640656, 2016.

29- FURLAN J.C., NOONAN V., CADOTTE D.W. and FEHLINGS M.G.: Timing of decompressive surgery of spinal cord after traumatic spinal cord injury: An evidence-based examination of pre-clinical and clinical studies. J. Neurotrauma, Aug., 28 (8): 1371-99. doi: 10.1089/neu.2009. 1147. Epub. 2010 Mar. 4. PMID: 20001726; PMCID: PMC3143409, 2011.

30- PASSIAS P.G., POORMAN G.W., SEGRETO F.A., JALAI C. M., HORN S.R., BORTZ C.A., VASQUEZ-MONTES D., DIEBO B.G., VIRA S., BONO O.J., De La GARZARAMOS R., MOON J.Y., WANG C., HIRSCH B.P., ZHOU P.L., GERLING M., KOLLER H. and LAFAGE V.: Traumatic Fractures of the Cervical Spine: Analysis of Changes in Incidence, Cause, Concurrent Injuries, and Complications Among 488,262 Patients from 2005 to 2013. World Neurosurg. 2018 Feb.; 110: e427-e437. doi: 10.1016/j.wneu.2017.11.011. Epub 2017 Nov. 11. PMID:29138069, 2018. 


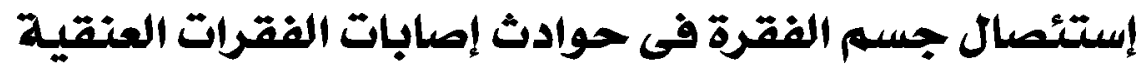

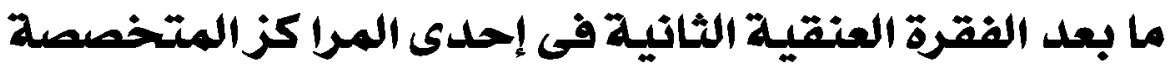 فى إحلى دول العالم الثالث الثالث الهرل}

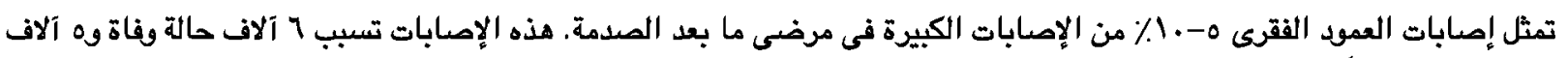

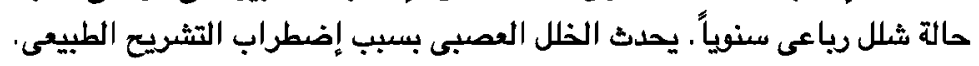
هدف العمل: إستئصال جزء من عنق الرحم هو إجراء شائع لجراحة العمود الفقرى يستخدم لفك ضغط الحبل الشوكى فى العديد من

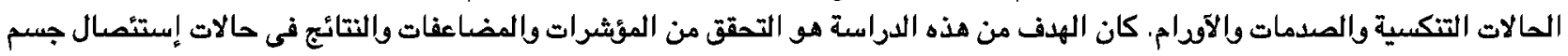
عنق الرحم السابقة في مركز واحد.

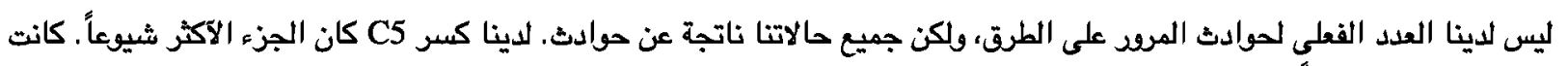

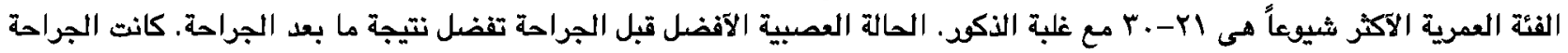

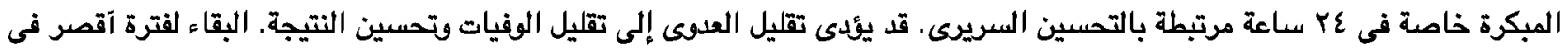

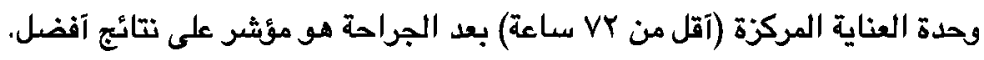

